\title{
Memoria, Historia, Saberes de la Convivencia Del saber con/vivir de la literatura
}

\section{Memory, History, Knowledges of the Living Together. On To Know Living Together of the Literature}

\author{
OTTMAR ETTE
}

Universidad de Potsdam

\begin{abstract}
RESUMEN. Las culturas y sociedades desarrollan en cierto momento y dentro de algún contexto un saber con/vivir, que no solamente tiene que enriquecerse continuamente, sino que también se puede perder o ser destruido en mayor o menor medida. La literatura es, en su calidad de acervo altamente dinámico e interactivo y generador de saber de vida, aquella formación de conocimiento políglota en la que de forma densa se pueden encontrar gnosemas elementales de un saber vivir, un saber sobre/vivir y un saber con/vivir, que son de crucial importancia para el futuro de nuestro planeta y sus tan diferentes manifestaciones de vida.
\end{abstract}

Palabras clave: Memoria, historia, saber, convivencia, literatura, Vargas Llosa, diversidad cultural.
Abstract. Cultures and societies develop in a certain moment and within a certain context an awareness of how to live together, which not only has to be enriched continuously, but can also be lost or destroyed to a greater or smaller measure. Literature is, in its capacity as highly dynamic and interactive heritage and generator of life knowledge, that multilingual wisdom, which in dense form can find basic gnosemes of a good living, knowing how to survive and how to live together, which are crucial for the future of our planet and its very different manifestations of life.

Key words: Memory, history, knowledge, live together, literature, Vargas Llosa, cultural diversity.

\section{En busca de la convivencia perdida}

El escritor peruano e intelectual beligerante Mario Vargas Llosa, quien fuera galardonado en 2010 con el premio Nobel de Literatura, nos ofreció en 2000 con su novela La Fiesta del Chivo un voluminoso texto narrativo que, por lo menos a primera vista, habla del rotundo fracaso en materia de la convivencia. El autor, nacido en 1934 y oriundo de Arequipa logra, con ese virtuosismo y ese guiño de ojo burlón que le son propios y con el empleo de un sinnúmero de alusiones intertextuales que revisten la novela, inscribirla en el subgénero de la novela de la dictadura, porque devela al lector y también a Urania, la protagonista, un mundo - su mundo - azotado por esa devastado- 
ra violencia que había caracterizado la República Dominicana a lo largo de una de las dictaduras militares más sangrientas de América Latina. Durante la era del dictador Trujillo, a quien el pueblo había tildado de «Chivo» en reconocimiento de su excesiva virilidad, no solamente fracasa de forma brutal y espectacular una convivencia pacífica a nivel nacional e internacional - amén de que la «tolerancia» benevolente que los Estados Unidos mantuvieron por décadas para con el genocida Trujillo únicamente se puede comprender como consecuente apoyo al sinnúmero de asesinatos, de represalias y saqueos cometidos - sino también en el contexto familiar e individual. Esto lo demuestran desde un principio los movimientos interiores y exteriores de la protagonista. El solitario ejercicio del jogging matutino practicado por Urania, quien ha vuelto a Santo Domingo, antes llamado Ciudad Trujillo, con el fin de pasar unos días allí, sin que los demás miembros de la familia que radican en la isla tuvieran noticia de su llegada, revela la enorme soledad con la que esta mujer, todavía muy atractiva, se mueve por el camino de su vida. A causa de un acontecimiento que vivió en carne propia siendo ella una adolescente de familia acomodada es incapaz de tener cualquier tipo de convivencia íntima.

La figura pendular de la isla, tanto en su calidad de isla-mundo, esto es, un mundo cerrado en sí mismo, como también en su carácter de mundo de islas o archipiélago, entrelazado de forma muy compleja con otras islas y continentes, es la que determina esta estructura novelesca, que - tal y como se ha podido mostrar en otra ocasión 1 - ha sido acuñada por estructuras y patrones o modelos fractales. Desde la isla de Manhattan, que para Urania se ha convertido desde hace mucho en su segundo hogar y patria, la protagonista viaja al Caribe y ya a su llegada se percata de la temporalidad y espacialidad propia e inherente a lo insular que, aunque familiar, le resulta tan ajenas; un mundo, en el que una mujer atractiva y soltera sigue siendo motivo de escándalo, pero en el que la omnipresente dictadura de Trujillo, cuyos símbolos para ella son ubicuos y la asaltan desde todas las formas de expresión urbanas y humanas, simplemente se ignoran y borran de la conciencia colectiva. La amnesia es el fundamento sobre el que se apoya la convivencia en la era post-trujillista. ¿Qué necesidad tienen la familia o los habitantes de la República Dominicana de seguir ocupándose de la era del Chivo? ¿Y no tuvo la dictadura también sus lados positivos?

Pero Urania en su papel de imán del saber, de planeta del conocimiento no quiere y no debe olvidar, no quiere y no puede desatender la historia de su cuerpo, de su familia, de su isla. Está en busca de un tiempo perdido que no quiere transcurrir. A lo largo de los años que han pasado desde que las monjas norteamericanas la habían salvado de las garras del dictador, de

1 Véase aquí el capítulo siete en Ette, Ottmar: ZusammenLebensWissen. List, Last und Lust literarischer Konvivenz im globalen Maßstab (ÜberLebenswissen III). Berlin, Kulturverlag Kadmos, 2010. 
aquel potentado que, aunque viejo y achacoso, seguía siendo una amenaza, y la habían llevado clandestinamente a los Estados Unidos donde ella logró hacer una brillante carrera profesional después de sus estudios en Harvard, no había dejado de examinar todos los detalles de aquella dictadura patriarcal, en la que antaño su padre había jugado un papel a la vez destacado y tan poco honroso.

Con tenacidad y obsesión trata de develar aquellos mecanismos de poder y violencia que habían acuñado tan profundamente la vida de la República Dominicana, la de su familia, la de sus padres y sobre todo su propia vida, la intuición que tiene sobre su propio cuerpo, su saber sobre el cuerpo. El amplio y lujoso departamento de la abogada del Banco Mundial se encuentra «en su tierra» en Manhattan repleto de libros, lo cual envuelve a esta atractiva mujer en un aura intelectual y cultivada. Sin embargo, hay un más allá de este «mundo de libros» puestos en escena que transgrede el aspecto social. En su dormitorio, en el que jamás ha compartido la cama con otro hombre y donde nunca ha querido sentir el amor, se hallan, como en una isla en el centro de Manhattan, todos aquellos libros que tratan de su isla natal y Urania sabe muy bien, cuáles han sido los crímenes que cometió Trujillo, apoyado activamente por el padre de Urania, en contra de Haití, país con el que la República Dominicana comparte la Isla Hispaniola. Los testimonios, ensayos y memorias sobre la historia de la dictadura ilustran y tocan muchos aspectos, pero se mantienen alejados del saber de vida de Urania.

En estos libros, que contienen los más diversos aspectos de la dictadura de Trujillo, aparece una y otra vez un hombre llamado Cabral, al que algún día se le dio el apodo de «Cerebrito». Y se trata de nadie más que del padre de Urania, que había servido al «Chivo» o al «Jefe» como le llamaba entonces, como cerebrito en el diseño de las estructuras totalitarias de violencia y le apoyaba en las distintas funciones de poder. ¿Una amistad entre hombres? De ninguna manera. Cabral, quien al parecer sin motivos aparentes cae en desgracia casi al final de la era dictatorial, había podido gozar de todos los privilegios durante el régimen totalitario y nunca pudo imaginarse que su apodo «Cerebrito» no sólo iba a significar su ascenso sino también su final, porque sufre un ataque de apoplejía del que ya no se recuperará y que le condena a escuchar, impotente y mudo, las recriminaciones que Urania le hace al volver a la casa de la familia, a la casa de su infancia perdida:

Mi departamento de Manhattan está lleno de libros - retoma Urania-. Como esta casa, cuando era niña. De derecho, de economía, de historia. Pero, en mi dormitorio, sólo dominicanos. Testimonios, ensayos, memorias, muchos libros de historia. ¿Adivinas de qué época? La era de Trujillo, cuál iba a ser. Lo más importante que nos pasó en quinientos años. Lo decías con tanta convicción. Es cierto, papá. En estos treinta y un años cristalizó todo lo malo que arrastrábamos, desde la conquista. En algunos de esos libros apareces tú, como un personaje. Secretario de estado, senador, presidente del Par- 
tido Dominicano. ¿Hay algo que no fuiste, papá? Me he convertido en una experta en Trujillo. En lugar de jugar bridge, golf, montar a caballo o ir a la ópera, mi hobby ha sido enterarme de lo que pasó esos años. Lástima que no podamos conversar. Cuántas cosas podrías aclarame, tú que los viviste de bracito con tu querido Jefe, que tan mal pagó tu lealtad. Por ejemplo, me hubiera gustado que me aclararas si Su Excelencia se acostó también con mi mamá ${ }^{2}$.

En la escena clave de este primer reencuentro cara a cara con el padre, el hombre que antaño fuera tan poderoso en el ámbito familiar y nacional, no solamente se remite implícitamente al hecho de que «Cerebrito», para congraciarse con su «Jefe», le ofreciera a su hija para una complaciente desfloración, sino también se considera la posibilidad de que el padre, para no caer en desgracia con el jefe, hubiera practicado este mismo procedimiento con su esposa, la difunta madre de Urania. La lúgubre sospecha de una escenografía en la que, ante el telón de fondo de haber sido ella una ofrenda patriarcal, hubiera indicios de un «ofrecimiento a plazos» del cuerpo de la madre, ponen de manifiesto que en esta pequeña familia se han hecho añicos y destrozado los fundamentos para una convivencia, una confiable convivencia. Es insoportable pensar que el hombre en el poder se hubiera convertido no solamente en el alcahuete de su hija, sino antes también de su mujer. ¿Sería posible pensar en una convivencia familiar después de una historia en la que el padre de familia usa a sus mujeres como ofrenda en aras de satisfacer la conocida patología sexual del dictador, y las somete a la prostitución en nombre de cierta razón de estado y el mantenimiento del propio bienestar económico?

Esta horrible experiencia, estos horribles recuerdos, sin embargo, sólo representan una de las caras de aquel saber, cuya inacabable e inconclusa plenitud trata de alcanzar Urania. Ella se ha adueñado de un amplísimo saber historiográfico, politológico y sociológico sobre la República Dominicana con la esperanza de poder entender todo lo posible de aquello que la moldeó a ella y su propia vida. Pero también para comprender, cómo fue posible que un despotismo tan sanguinario pudo instaurarse en la República Dominicana y se pudo mantener en el poder por tantas décadas y donde incluso los valientes autores del atentado perpetrado contra el Chivo en el camino a su «Casa de Caoba» donde quería desflorar a otra virgen, fueron perseguidos, torturados y asesinados de la peor manera por el régimen. Mario Vargas Llosa se inspira aquí en el íncipit del Facundo de Domingo Faustino Sarmiento, publicado en 1845, en el que se escenifica la invocación de la sombra de Facundo Quiroga, que quiere saber del caudillo ya muerto la solución del aparentemente insondable gran enigma: ¿Cómo fue posible toda esa bárbara violencia?

\footnotetext{
2 Vargas Llosa, Mario: La Fiesta del Chivo, Madrid, Alfaguara, 2006, p. 67.
} 
Esta interrogante, que acompaña toda la historia de la literatura latinoamericana, se ha convertido para Urania en la pregunta vital y de supervivencia. La dominicana, que procede de una aparentemente «buena familia», liga su propio saber sobre las experiencias, que en parte se ha convertido en su saber sobre su propio cuerpo - que no ha compartido con hombre algunocon un saber ganado a través de la lectura de libros de consulta y tratados científicos, por lo que lo experimentado y lo leído se unen correlativamente. Sin embargo, aún falta aquel elemento determinante del saber que le permita escaparse del infortunio de su exitosa vida a fin de que todos esos horribles recuerdos que opacan sus éxitos se puedan abrir hacia algo venidero, a un futuro estructurable. La pregunta de Urania - cuyo nombre sin lugar a dudas introduce aquí la mitología griega y con ello remite a la memoria- es una doble pregunta: ¿Por qué fue posible toda esta violencia? ¿Se puede volver a una convivencia después de esto?

Aquí lo importante no es la historia, no es la problemática de la memoria $^{3}$, un tema sustancial para Mario Vargas Llosa, sino que se trata de mucho más. No sólo se pretende lograr la reconstrucción de lo vivido en el pasado, sino también la construcción de lo que en un futuro se vivirá. Esto no significa que trabajar individual o colectivamente la historia, esto es, una «labor en el mito» ${ }^{4}$ de la era y de la figura de Trujillo no tenga un valor intrínseco o sea superflua. Al contrario: esto conforma la base imprescindible para cualquier tratamiento de la historia tanto del pasado como del presente y del futuro. Pero únicamente es el requisito para adquirir aquel saber que busca Urania. ¿De qué forma se puede expresar este conocimiento, cómo se puede modelar y hacer vivenciable?

No resulta demasiado difícil encontrar un vínculo entre los estantes repletos de libros, cuya intensa lectura absorbe a Urania y los kilómetros de libros que consultó el autor real, Mario Vargas Llosa para realizar su como siempre escrupulosa y sistemática investigación, sobre todo en la biblioteca del Instituto Ibero-Americano Patrimonio Prusiano en Berlín antes de redactar su novela La fiesta del Chivo. Si el poeta docto peruano, quien como se sabe escribió su tesis de doctorado sobre la obra de uno de sus antiguos compañeros Gabriel García Márquez ${ }^{5}$ y ha alternado desde ese momento su creación artística con

3 Véanse por ejemplo sus observaciones en una entrevista: «Yo creo que pocos escritores escriben sólo a partir de la imaginación; creo que la memoria es un ingrediente esencial de la creación literaria, que uno recurre siempre a un material que está almacenado allí en el recuerdo, y que busca en esas imágenes situaciones, personajes, la materia prima a partir de la cual fantasea. Por lo menos esa ha sido mi experiencia. Todos los libros que he escrito, incluso los que parecen más desconectados de la realidad objetiva, tienen siempre unas raíces en la experiencia personal.» En Bernabé, Diego: Mario Vargas Llosa y su última novela, «La Fiesta del Chivo»: escribir sobre la dictadura de Trujillo es escribir sobre todas las dictaduras. http://www.espectador.com/text/especial/vargasll.htm (18.10.2010).

4 Véase Blumenberg, Hans: Arbeit am Mythos, Frankfurt am Main, Suhrkamp, 1979.

5 Vargas Llosa, Mario: García Márquez: Historia de un deicidio, Barcelona, Ed. Barral, 1971. 
trabajos de investigación literaria sobre Flaubert ${ }^{6}$ o Arguedas ${ }^{7}$, sobre Victor Hugo ${ }^{8}$ u Onetti ${ }^{9}$, sobre Tirant lo Blanc ${ }^{10}$ o Cervantes ${ }^{11}$, y realizaba sus trabajos preparatorios con la misma meticulosidad con la que su admirado maestro Flaubert se dedicara a los suyos, entonces lo hacía a sabiendas de que el tratamiento sistemático e investigativo de la memoria no iba a ser suficiente para crear aquel saber vivo al que aspira su figura Urania. Y probablemente habrá sido la intensa estadía en Berlín, en el Wissenschaftskolleg y el ya mencionado Instituto Ibero-Americano que hiciera que el autor peruano se tropezara con aquella asociación fundada en 1888, cuyas metas siguen fielmente la tradición de Alexander von Humboldt y que lleva el nombre de la protagonista de $L a$ fiesta del Chivo: «Urania». Si se consulta la página principal en la Internet (www.urania.de) de esta venerable y afortunada institución, hallamos un lema que nos podrá causar sorpresa o no, en el que se vincula la expresión del saber con la locución de la vida: «vivir el nuevo saber».

Urania es sin lugar a dudas, una figura de conocimiento: en busca del tiempo perdido configura una y otra vez el saber en vivo, en persona y con esto precisamente hace que el saber en su procesualidad se convierta en una vivencia para sus lectores. Al igual que Vargas Llosa, también ella trata de ampliar a través de su viaje a la República Dominicana su conocimiento biforme (o doblemente generado) ya perfilado por medio de vivencias actuales e investigaciones en el lugar. El hecho de que la enorme biblioteca en el dormitorio de Nueva York no contenga una sola novela es un claro indicio para la «disposición» de crear, en medio de aquel mundo de libros sobre la República Dominicana, su propia novela de búsqueda, en la que ella se vale de su propia figura literaria.

Lo anterior lleva a una confrontación entre diferentes niveles de tiempo, de espacio y de vivencias de moción y conmoción, tal y como se refleja en la escena del reencuentro entre padre e hija, una escena de grandiosidad literaria:

La recibe una luz viva, que irrumpe por la ventana abierta de par en par.

La resolana la ciega unos segundos; después, va delineándose la cama cubierta con una colcha gris, la cómoda antigua con su espejo ovalado, las fotografías de las paredes - ¿cómo conseguiría la foto de su graduación en 1975.

6 Vargas Llosa, Mario: La orgía perpetua: Flaubert y Madame Bovary, Madrid, Taurus,

7 Vargas Llosa, Mario: La utopía arcaica: José María Arguedas y las ficciones del indigenismo, México, Fondo de Cultura Económica, 1996.

8 Vargas Llosa, Mario: La tentación de lo imposible: Victor Hugo y «Los miserables», Madrid, Alfaguara, 2004.

9 Vargas Llosa, Mario: El viaje a la ficción. El mundo de Juan Carlos Onetti, Madrid, Alfaguara, 2008.

10 Vargas Llosa, Mario: Carta de batalla por Tirant lo Blanc. Prólogo a la novela de Joanot Martorell, Madrid, Alianza Editorial, 1969, pp. 9-41.

11 Vargas Llosa, Mario: Cervantes y la ficción - Cervantes and the Craft of Fiction, Basel, Schwabe \& Co. Verlag, 2001. 
Harvard? - y, por último, en el viejo sillón de cuero de respaldar y brazos anchos, el anciano embutido en un pijama azul y pantuflas. Parece perdido en el asiento. Se ha apergaminado y encogido, igual que la casa. La distrae un objeto blanco, a los pies de su padre: una bacinilla, medio llena de orina.

Entonces tenía sus cabellos negros, salvo unas elegantes canas en las sienes; ahora, los ralos mechones de su calva son amarillentos, sucios. Sus ojos eran grandes, seguros de sí, dueños del mundo (cuando no estaba cerca el Jefe); pero, esas dos ranuras que la miran fijamente son pequeñitas, ratoniles y asustadizas. Tenía dientes y ahora no; le deben haber sacado la dentadura postiza (ella pagó la factura hace algunos años), pues tiene los labios hundidos y las mejillas fruncidas casi hasta tocarse. Se ha sumido, sus pies apenas rozan el suelo. Para mirarlo ella tenía que alzar la cabeza, estirar el cuello, ahora, si se pusiera de pie, le llegaría al hombro ${ }^{12}$.

La luz que irrumpe por la ventana, deslumbra: es una luz viva, porque la vida alumbra y deslumbra a la vez, ilumina y expone todo aquello que, no siempre sin dolor, nos lleva a la cognición. El deterioro del pasado no sólo se consuma en la estructura fractal de la casa, sino que de forma mucho más radical en la del cuerpo: el patriarca se ha encogido hasta convertirse en un enano, ha perdido sus dientes, su vigor, todo su poder y también su lengua y el dominio sobre su propio cuerpo y el de los demás. Es lo que ya no es y no puede dejar de ser.

El antaño admirado cuerpo del padre ya no es la vara con la que se mide todo; el cuerpo de Urania, en otro momento flaco y poco desarrollado ha crecido en la medida en que el del padre se encogía. Ella ha asumido el poder y con ello también las cuentas del padre. En esta dramaturgia casi clásica del reencuentro presenciamos la escenificación del saber sobre la experiencia que en su corporeidad no encuentra otro par. El abuso del cuerpo de la propia hija y quizá también del cuerpo de su esposa ha repercutido con contundencia en su propio cuerpo y el ataque afectó a «Cerebrito» precisamente allí donde se invalidaron todos los fundamentos de la convivencia: el cerebro.

Este conocimiento no se adquiere por medio de la investigación en archivos y bibliotecas; y el término «Erfahrungswissen» (saber sobre la experiencia) no expresa del todo qué es lo que quiere dar a entender esta escena y más aún, la literatura: un saber vivencial que no es sólo una dimensión esencial, sino quizá la decisiva de un saber de vida específico. La interpretabilidad de la relación entre los dos polos terminológicos en esta expresión en su calidad de genitivus obiectivus, partitivus, possessivus, qualitatis y finalmente de genitivus subiectivus debe desvelar la polisemia estructural de este término transgresor de fronteras y no soslayarla. Esto es, que se piensa en categorías de un saber sobre la vida entendido como un saber de la vida sobre sí misma, de un saber como parte esencial de la vida (y la supervivencia), como una cualidad fundamental de la vida en sí, de un saber hacia la vida y un saber en

12 Vargas Llosa, Mario: La Fiesta del Chivo, op. cit., p. 65. 
la vida. Sin las dimensiones de lo estético y aiestético no se podrá adquirir un saber de esa índole.

Por eso, fue el retorno a la isla que al principio de la novela aparece en cierto modo emergiendo del mar, la visita a la casa paterna y la propia niñez perdida y la escena del reconocimiento y la cognición, la anagnórisis del enfrentamiento cara a cara de padre e hija, lo que actualiza y vivifica el pasado, que para Urania sigue siendo - y ahora más que nunca - terriblemente doloroso. Urania se da cuenta (el texto novelesco rara vez lo devela), casi está segura, de que no es improbable que ella sea hija del Chivo y que éste no la pudo poseer porque justamente en ese instante le abandonan las fuerzas viriles a este todopoderoso dictador entrado en años. Abundan aquí los padres convertidos en traidores. La repentina pérdida de la virilidad, que a Urania le aseguró su virginidad pero le deparó una intocabilidad, la encara vívidamente al estar frente al cuerpo inerte de su padre y le da la posibilidad de vivenciar intensamente lo que resta del principio del potentado patriarcal, las sobras de aquél, a quien su padre había servido con tanta devoción, del hombre a quien llamaban «el Generalísimo, el Benefactor de la Patria, el Padre de la Patria Nueva, el Restaurador de la Independencia Financiera» ${ }^{13}$ antes de que perdiera la vida en el atentado. El silencioso desafío de Urania es evidente: ¿De qué manera se podrá impedir y superar esta intocabilidad, que en cierto sentido también acarrea consigo la incapacidad de convivir (por lo menos de manera íntima)?

Sólo es la luz viva, que ciega más de una vez a nuestra abogada de Manhattan en el cuarto de su padre, la que ya en el último capítulo le dará el valor de narrarles a los miembros femeninos de su familia, cuyas cartas nunca había contestado, sobre esa otra casa, la «Casa de Caoba». Detrás de los muros resguardados militarmente se encontraban aquellos interiores llenos de kitsch y poder, de los que Urania sólo puede hablar con mucho esfuerzo, porque el lastre de lo vivido y el revivirlo actualmente pesa demasiado. Sin duda: para Urania es la historia más difícil de contar, un relatar que tiene que luchar contra la censura que se impone a sí misma y la de la familia (personificada por la tía Adelina). Pero es asimismo aquel narrar el que le da la oportunidad, si no de volver a la isla y convivir con la familia, por lo menos de establecer un contacto continuo con la pequeña Mariana, que con tanta fascinación escucha su historia:

Cuando Urania se despide de Marianita, ésta la abraza como si quisiera soldarse, hundirse en ella. El cuerpecito filiforme de la chiquilla tiembla como un papel.

Yo a ti te voy a querer mucho, tía Urania - le susurra en el oído y Urania siente que la embarga la tristeza- Te voy a escribir todos los meses. No me importa si no me contestas» ${ }^{14}$.

13 Ídem., p. 518.

14 Ídem., p. 525. 
Aquí resulta más que evidente: la escena de la última página de la novela no está vinculada a una promesa de felicidad, no significa la segura liberación de aquella tristeza que una y otra vez sobrecoge a Urania. Pero alberga la esperanza de poder entablar relaciones o de restaurar las existentes; vínculos que, teniendo en cuenta lo sucedido no se hubieran podido mantener. En el cuerpo aún en desarrollo de Marianita descubre la protagonista un alter ego como plataforma de comunicación, que transforma el poder de narrar en uno que puede curar a Urania. En busca de la convivencia perdida ha nacido en el acto del narrar un nuevo saber, que trasciende en mucho la problemática de la memoria. Este saber de vida narrativo de múltiples significados constituye la base para una nueva convivencia.

\section{En busca de una comunidad polilógica}

No es ninguna casualidad que las reacciones de la niña descritas en la cita anterior sean más bien corporales, en tanto la narración de Urania acerca del cuerpo afecta directamente el cuerpo de su interlocutora. Empieza a temblar cual pedazo de papel. El vínculo que se establece aquí con la escritura se retoma inmediatamente y se transforma en promesa: la pequeña Marianita promete escribirle a su tía, aunque ésta no le conteste, esto es, que no quiera escribir. Esta distinción entre hablar y escribir es muy importante en Vargas Llosa y se puede rastrear en muchos de los textos narrativos y ensayísticos del autor de El hablador.

Mario Vargas Llosa introduce su libro sobre Juan Carlos Onetti, El viaje a la ficción publicado en 2008, intencionalmente con una ficción de la historia de la humanidad y despliega así en las primeras páginas de este extenso estudio sobre el autor uruguayo el devenir del ser humano desde sus principios hasta su estado actual de civilización ultradesarrollada. Vargas Llosa diferencia allí con precisión entre la coexistencia y la convivencia al aseverar que «coexistir no es todavía convivir» ${ }^{15}$, porque el convivir presupondría un «elaborado sistema de comunicación» ${ }^{16}$. Y de hecho: la convivencia trasciende en mucho a la coexistencia.

La reflexión histórico-cultural implica una de carácter histórico-filológica. Es sólo con la adquisición de la lengua que el hombre puede realizar el paso decisivo en el «proceso de desanimalización» ${ }^{17}$, que puede nacer «una sociedad, una comunidad de gentes que, por ser hablantes, son pensantes» ${ }^{18}$. Una verdadera comunidad surge sólo a través de la voz de un contador de his-

15 Vargas Llosa, Mario: El viaje a la ficción. El mundo de Juan Carlos Onetti, Lima, Santillana Editores 2008, p. 12.

16 Íbid.

17 Ídem., p. 14.

18 Íbid. 
torias, alrededor del cual se reúnen las personas para darle vuelo a la imaginación e ingresar en aquel «vivir otra vida - una vida de a mentiras, que construyen en silenciosa complicidad con el hombre o la mujer que, en el centro del escenario, fabula en voz alta» ${ }^{19}$. Es en este narrar en el que Vargas Llosa ha descubierto desde hace mucho la genuina base de la literatura (y, podríamos añadir, una base con fundamento en la ciencia de la vida). Casi se podría hablar de una escenografía en la tradición de la parábola de la cueva de Platón o del «claro» de Heidegger:

Para mí, la idea del despuntar de la civilización se identifica más bien con la ceremonia que tiene lugar en la caverna o el claro del bosque en donde vemos, acuclillados o sentados en ronda, en torno a una fogata que espanta a los insectos y a los malos espíritus, a los hombres y mujeres de la tribu, atentos, absortos, suspensos, en ese estado que no es exagerado llamar de trance religioso, soñando despiertos, al conjuro de las palabras que escuchan y que salen de la boca de un hombre o una mujer a quien sería justo, aunque insuficiente, llamar brujo, chamán, curandero, pues también sueña y comunica sus sueños a los demás para que sueñen al unísono con él o ella; un contador de historias ${ }^{20}$.

Pero, ¿qué sucede, si no son a las formas de narración oral a las que nos enfrentamos, sino a la literatura? Consideremos antes que nada lo siguiente: en la investigación actual sobre la narración se ha perfilado la opinión de que «la literatura y la convivencia están íntimamente vinculadas» y que este vínculo entre los dos puede considerarse «obvio» ${ }^{21}$. En ello también se podrían estimar como muy aceptadas las conclusiones de Jerome Bruner, en tanto asevera que contar «es más un medio para identificar el problema que para solucionarlo» ${ }^{22}$. Aunque la literatura - como suele propalarse- muestre una distancia mayor hacia la vida que por ejemplo las narraciones cotidianas y con eso esté «menos apegada a la vida» e incluso «más alejada de la vida», no debemos dejarnos seducir por este tipo de argumentos y presuponer una absoluta desvinculación entre literatura y vida, muchas veces también más allá de una estética autónoma. Porque pasa todo lo contrario. Así Vera Nünning aclara con toda razón lo siguiente:

Si en lo cotidiano manejamos con economía nuestro tiempo y confiamos por regla general en los moldes de interpretación conocidos, mientras nos cerramos a lo que va a contrapelo con aquellas formas de ver de las que nos hemos encariñado, entonces al ocuparnos de la literatura podemos imaginarnos mundos alternativos - mundos que nos desvelan nuevas formas de interpre-

19 Ídem., p. 15.

20 Íbid.

21 Nünning, Vera: «Literatur - Erzählen - ZusammenLeben», en Ette, Ottmar (ed.): Wissensformen und Wissensnormen des Zusammenlebens, Actas del Congreso en el Institute for Advanced Studies en Freiburg, Berlin-New York, Walter de Gruyter, 2011 (en imprenta), p. 1.

22 Véase para ello ídem., p. 12. 
tación del mundo - . La aparentemente mayor distancia hacia la vida, por lo tanto lleva a una mayor cercanía, a una capacidad de impacto más intensa por parte de las narraciones literarias ${ }^{23}$.

En este sentido, cuando Vargas Llosa habla de aquella otra vida, de aquellas otras vidas que se nos manifiestan más allá de nuestra vida cotidiana y real a través de la narración y en forma más densa, a través de la literatura, no se deben considerar de ninguna manera como una fuga de la realidad, del mundo de los hechos de la historia, en el sentido que le da Aristóteles. Sin embargo, también aquí se trata de un movimiento, que por medio de un proceso paradójico de un distanciamiento acercador lleva cada vez más profundamente al centro de la vida, en tanto se excluye cualquier función consejera. El saber de vida de la literatura se caracteriza precisamente por el hecho de que no representa un saber de actos de transferencia inmediata a la vida.

Es precisamente gracias al vínculo y la densificación de las diferentes formas y normas de conocimientos y las más diversas formas y normas de comportamiento que la literatura pone en movimiento y en circulación su saber específico: un saber de vida, que se encuentra en una relación llena de tensión con la vida y por eso su referencia no puede ser indiferente.

Sin duda, podemos reconocer aquí el poder real de la literatura o, mejor dicho, su contra-poder vivo y rebelde contra el poder de la historia: su capacidad de inventar un mundo que no se encuentre ni separado de aquello que con tanta ligereza llamamos «la vida real», ni en conjunción con ella.

En su ensayo sustancial sobre Cervantes y la ficción, Vargas Llosa trató de llegar a la médula de lo que él entiende por la fuerza estética de la ficción:

Gracias a ella somos más y somos otros sin dejar de ser los mismos. En ella nos disolvemos y multiplicamos, viviendo muchas más vidas de las que tenemos y de las que podríamos vivir si permaneciéramos confinados en lo verídico, sin salir de la cárcel de la historia ${ }^{24}$.

Lo que Vargas Llosa consideraba la «cárcel de la historia» desde el punto de vista de aquella verdad de las mentiras ${ }^{25}$ en la que se podría ubicar la literatura, nos lo despliega en innumerables novelas y cuentos, y precisamente en aquel mundo lleno de bestialidad, de persecución, de tortura y aniquilamiento que nos desvela cruda, inmisericorde y magistralmente La Fiesta del Chivo. Se refiere con ello a la historia, que en el sentido del noveno capítulo de la Poética de Aristóteles, se desarrolla precisamente de la manera como sucede o ha sucedido. Ella es el transcurso, el inexorable transcurrir de lo particular, de lo que nos concierne, nos golpea y de lo que no podemos huir, tal y como

23 Ídem., p. 9. Para facilitar el acceso a las citas en alemán, éstas han sido traducidas literalmente (RSM).

24 Vargas Llosa, Mario: Cervantes y la ficción - Cervantes and the Craft of Fiction, op. cit., p. 19.

25 Véase Vargas Llosa, Mario: La verdad de las mentiras, Barcelona, Seix Barral, 1990. 
le sucediera a Urania con su padre y el jefe de éste. La «cárcel de la historia» se refiere a esta represión, se refiere a la «inmovilización» (Fest-stellung) por una sola y predominante lógica, por una estructura monolítica, que aparentemente no se puede fracturar y a la que — según nos quiere hacer creer la «situación-de-los-hechos» no tenemos nada que oponer.

Sin embargo, según la famosa locución aristotélica, la literatura se propone representar la manera de cómo hubieran podido suceder las cosas ${ }^{26}$, insiste en considerar todas las fuerzas simultáneas existentes, demanda otras lógicas que hubieran podido entrar en juego de otra manera o más intensamente. Precisamente aquí se le considera más seria y filosófica que a la historiografía. Y en una figura de pensamiento que seguramente puede considerarse paradójica, el filósofo griego veía que aunque la literatura (o la poesía) apuntaba hacia la develación del punto de vista de una sola persona con su biografía, con su formación, su criterio, su saber de vida la posibilidad de aprehender lo general y no lo particular (como sucede en la historia): esto es, retratar en una persona al hombre en vez de perderlo constantemente de vista en su «cárcel de la historia» particular y tan diversa. Esto es precisamente lo que constituye el espacio de experimentación, el carácter profundamente experimental de la literatura. Porque al enfocar un cierto saber de vida se hace representable un saber sobre la vida, que con seguridad rebasa en mucho el enfoque elegido. La literatura es, porque es mucho más de lo que es una vida que una y otra vez se va reordenando al ser contada, que en su vivencia, en su hallazgo y su invento no se deja reducir a una lógica totalitaria y abarcadora, si siquiera a lo que en este país muchas veces se le llama, cual fuego fatuo, una Leitkultur (cultura guía).

Ningún invento del ser humano, dice Vargas Llosa en su análisis de Juan Carlos Onetti, hubiera sido posible sin este invento elemental de la ficción - precisamente en las horas del peor miedo y pánico-, cuando en los albores de la civilización nos encontrábamos «apretados contra otros cuerpos humanos en busca de calor» en las cavernas y seguíamos los cuentos de los contadores que nos invitaban a compartir sus viajes mentales ${ }^{27}$. El contar se convierte en un medio para sobrevivir, porque hace que los cuerpos se apretujen, porque genera calor humano, porque crea una comunidad que, gracias a las historias es capaz de desafiar a la historia.

Sin embargo, esto no quiere decir que debamos cerrar los ojos ante todas aquellas fuerzas negativas y destructivas que yacen ocultas en nuestra imaginación ${ }^{28}$. Más bien en esta capacidad del ser humano de inventar viajes humanos radica la posibilidad de crear comunidades guiadas por nuestros miedos, nuestras fobias y nuestros fantasmas.

\footnotetext{
26 Véase Aristoteles: Poetik, Stuttgart, Philipp Reclam, jun. 1982, pp. 29-31.

27 Vargas Llosa, Mario: El viaje a la ficción, op. cit., p. 26.

28 Ídem., pp. 26s.
} 
Todo eso somos también nosotros, pero lo disimulamos y negamos en nuestra vida pública, gracias a lo cual es posible la convivencia y la vida social, a la que tantas cosas debemos sacrificar para que la comunidad civilizada no estalle en caos, libertinaje y violencia ${ }^{29}$.

Y continúa:

Diversión, magia, juego, exorcismo, desagravio, síntoma de inconformidad y rebeldía, apetito de libertad, y placer, inmenso placer, la ficción es muchas cosas a la vez y, sin duda, rasgo esencial y exclusivo de lo humano, lo que mejor expresa y distingue nuestra condición de seres privilegiados, los únicos en este planeta y hasta ahora al menos, en el universo conocido, capaces de burlar las naturales limitaciones de nuestra condición, que nos condena a tener una sola vida, un solo destino, una sola circunstancia, gracias a esa arma sutil: la ficción ${ }^{30}$.

La ficción como rasgo esencial del hombre, lo fundamentalmente humano como expresión de su capacidad de inventar y asimismo de su infinito placer y sobre todo como requisito para formar una comunidad: éstas son las fuerzas que, en el sentido que le da Mario Vargas Llosa, logran liberar a la literatura y ponerla en movimiento. Estas reflexiones se pueden trasladar de la diferenciación binaria entre una y muchas vidas, entre nuestra vida real y la ficción a una estructuración más compleja y asimismo más abierta, en la que lo hallado (en cierto modo la «cárcel de la historia») construye, con lo inventado (esto es, la ficción), una relacionalidad con lo vivido y con lo que se vivirá que, en toda su contradicción, se perfila perfectamente en el mundo novelesco de este escritor recientemente galardonado con el premio Nobel.

De esta estructuración abierta es de donde se vuelve comprensible y vivible la interacción entre el lastre (esto es, la cárcel histórica, en la que tenemos que vivir), el ardid (con nuestras invenciones y ficciones) y el placer (aquel inmenso poder, que Roland Barthes logra desenvolver de manera sin igual en su estética del placer ${ }^{31}$ ). Es esta interacción la que nos permite comprender en la literatura desde sus comienzos - tal y como se perfila por ejemplo en las milenarias narraciones-marco de Las mil y una noches ${ }^{32}$ _ aquel específico poder (estético) del narrar y de la literatura, que le permiten a Sherezade interrumpir con un ardid la cadena de asesinatos de aquellas mujeres que el Sultán usa por una noche y abrirla hacia una convivencia fundamental, como la que caracteriza los principios polilógicos de las literaturas universales. Por-

29 Ídem., p. 29.

30 Ídem., p. 30.

31 Véase para ello la edición comentada de Barthes, Roland: Die Lust am Text, traducido y comentado por Ottmar Ette, Berlin, Suhrkamp Verlag, 2010.

32 Véase para ello el primer capítulo en Ette, Ottmar: ZusammenLebensWissen. List, Last und Lust literarischer Konvivenz im globalen Maßstab, Berlin, Kadmos, 2010. 
que la literatura en sus diversas expresiones guarda desde un principio un saber sobre la capacidad para la convivencia, un saber de la vida en la vida que moviliza y hace circular las más diversas formas y normas de comportamiento. La literatura habla aquí de una narración que salva vida y la engendra, porque apunta hacia una convivencia que es más que una coexistencia — no en balde, Sherezade y el sultán se convierten en una pareja que engendra hijos.

Volviendo por última vez a La Fiesta del Chivo, valdría la pena recapitular que la narración de Urania sobre las peores horas de su vida en la «Casa de Caoba» del dictador repercute directamente en el cuerpo de la pequeña Marianita para crear de nuevo una comunidad familiar que parecía ya no existir. El cuerpo de la niña se convierte en cierto modo en papel y se asocia con la escritura, pero no la escritura de Urania, sino la de Marianita, porque la propia Urania no escribe.

Aunque la figura de conocimiento de la novela probablemente tenga mucho en común con el autor real y externo al texto Mario Vargas Llosa, tal y como hemos podido apreciarlo, hay una diferencia elemental e imprescindible que no radica solamente en el hecho de que se trata de una figura inherente al texto y una externa al texto sino sobre todo en la circunstancia de que el autor oriundo de Perú escribe, mientras Urania, aunque lea mucho, no plasma nada literario sobre el papel. Mario Vargas Llosa logra en su novela, a diferencia de Urania, establecer el vínculo entre el hallar (amén del saber adquirido por la investigación en libros, documentos y otros testimonios) y el vivir (esto es, el saber sobre la experiencia en su dimensión pasada y actualizada) y a través del inventar, ampliarlo y transformarlo de tal forma que en esta triada se produzca un saber altamente densificado, que es el saber de la literatura: un saber vivir, que guarda en sí el saber sobrevivir y el saber convivir.

La convivencia se convierte así en una dimensión elemental de la literatura - y no sólo en el plano del contenido-. Por eso, no es únicamente la situación del narrar, la que nos remite a la parábola de la cueva que Vargas Llosa expone cuando habla de los seres humanos escuchando, muy juntos sus cuerpos, lo narrado, o el poder unificador de la ficción que nos lleva a un viaje (evasivo), sino la fuerza poli-lógica de la literatura que logra poner en movimiento y en circulación con enorme densidad (aunque no por ello reducido semánticamente sino más bien potenciado), un saber de las más diversas condiciones culturales de la convivencia, que puede ser adaptado o transformado en las más diferentes contextualizaciones de la recepción, esto es, que puede ser transformado tanto transnacionalmente como traslacionalmente. La convivencia pertenece al núcleo de aquel saber de vida que ponen a nuestra disposición las literaturas universales en su calidad de depósito infinitamente traducible y transformable, de un conocimiento que no se logra fijar por medio de una disciplina y que por ende es indisciplinable. La convivencia es el punto de fuga difícil de asir e inalcanzable en su forma plena, de todas aquellas lógicas, que no solamente coexisten en el texto, sino que se interpenetran 
en sus infinitas e interminables vinculaciones. Y por eso, no hay solamente una coexistencia de literatura y vida, sino una convivencia paradójica y polilógica.

No olvidemos en esta reflexión, que una convivencia en paz y diferencia a escala global es un enorme desafío para la humanidad en la actual (e inconclusa) cuarta fase de la globalización acelerada ${ }^{33} \mathrm{y}$ con ello para los ulteriores desarrollos del siglo XXI. La interrogante de una convivencia entre diferentes culturas, religiones, lenguas e identidades es una pregunta fundamental que las más diversas tradiciones de las literaturas universales desde la epopeya del Gilgamesh y Las mil y una noches han tratado de responder y han encontrado contestaciones. Resulta evidente que la literatura se puede comprender como un espacio de experimentación en el que se modela la convivencia. Este saber sobre la convivencia que ha recopilado y conservado la literatura y con el que una y otra vez ha experimentado, conforma un saber sobre las formas y normas de la convivencia que nos proporciona a nosotros, a nuestras sociedades y a nuestras comunidades, un saber de enorme envergadura que incluso sirve para asegurar nuestra supervivencia. Esto es así, porque la literatura logra desarrollar, en el triángulo entre el lastre históricamente acumulado, el ardid reflexionado estéticamente y el placer encauzado prospectivamente, su saber como saber sobre la experiencia, que no sólo hace vivible y experimentable todo lo escrito y publicable, sino también lo pensable y lo imaginable; esto es, está siempre abierta para la vida futura.

\section{En busca de la comunidad lingüistica perdida}

El sociólogo Wolf Lepenies, quien fue galardonado con el premio de la paz de los Libreros Alemanes, tal y como lo fuera Mario Vargas Llosa una década antes que él, en un ensayo desarrollado en 1993 acerca de la translación de las culturas había hecho hincapié en que «en nuestra era de las migraciones, de los contactos entre las culturas y los desplazamientos culturales» ${ }^{34}$, esto es, en aquella fase de la globalización acelerada que hemos denominado la cuarta, la «gran ilusión de 1989, que a partir de ahora el mundo marcharía incon-

33 Véase para ello Ette, Ottmar: «Wege des Wissens. Fünf Thesen zum Weltbewusstsein und den Literaturen der Welt», en Hofmann, Sabine y Wehrheim, Monika (eds.): Lateinamerika. Orte und Ordnungen des Wissens. Festschrift für Birgit Scharlau, Tübingen, Gunter Narr Verlag, 2004, pp. 169-184.

${ }^{34}$ Lepenies, Wolf: «Die Übersetzbarkeit der Kulturen. Ein europäisches Problem, eine Chance für Europa», en Haverkamp, Anselm (ed.): Die Sprache der Anderen. Übersetzungspolitik zwischen den Kulturen, Frankfurt am Main, Fischer Taschenbuch Verlag, 1997, p. 98. [,,in unserem Zeitalter der Wanderungen, der Kulturenkontakte und der Kulturverschiebungen“. (Si no se señala de otra manera, la traducción de las citas es mía, RSM). 
teniblemente hacia unificarse en una sociedad universal» ${ }^{35}$, se ha desvanecido. En vista de las fechas aquí nombradas queda fuera de dudas que se tiene que haber tratado de una ilusión muy efímera, cuyas exequias han ocupado más espacio en las publicaciones, que su tan breve (aunque pertinaz) existencia. Sea cual fuere la manera como se quiera valorar esto, en todo caso, en nuestra situación actual no podemos tener como meta «la igualación de las culturas», para la que Lepenies plantea una serie de fundados argumentos, «sino la traslación esencialmente recíproca» ${ }^{36}$.

Si contemplamos las relaciones entre las culturas a nivel internacional y las enfocamos desde el ángulo de la traducción y la traducibilidad, inmediatamente saltan a la vista las perseverantes asimetrías que han resultado de las expansiones militares, económicas, biopolíticas y culturales de Europa a lo largo de los siglos. Se podría hablar aquí en términos de Lepenies de un privilegio de ciertas lenguas y naciones europeas en la traslación y se podrían definir de la siguiente manera:

Las naciones poderosas - por regla general ellas mismas se consideraban civilizadas - eran siempre aquéllas que poseían una especie de privilegio de traslación; eran naciones que podían obligar a otras culturas a articularse en un idioma ajeno. Una disciplina como la etnología, que nace con la Ilustración, pero que apenas se profesionaliza siendo «hija» del colonialismo y del imperialismo, es por eso también una especie de ciencia de la traslación ${ }^{37}$.

En la línea de argumentación de la pregunta planteada en el ensayo sobre un «problema europeo» de tal especie y las «posibilidades europeas» vinculadas a él (que seguramente no se podrá abarcar tomando sólo en cuenta la perspectiva europea) es crucial no únicamente el hecho de que se ha agudizado la cuestión de la traducibilidad en el contexto de los procesos diferenciadores y desdiferenciadores que van en aumento y que se seguirán agudizando ${ }^{38}$, sino que asimismo se han agudizado «las diferencias entre las regiones» ${ }^{39}$ a nivel de sociedad universal, esto es, de la comunidad de naciones a nivel mundial. De allí resulta para el autor de Das Ende der Naturgeschichte el siguiente corolario:

El problema principal, por tanto, ya no radica en la manera en la que fomentamos el acercamiento de las culturas, sino más bien en la forma cómo podemos conservar su diferencia. Cuando en el siglo XVIII tanto Rousseau

35 Íbid. [,große Illusion von 1989, nun werde unaufhaltsam die Welt zu einer Weltgesellschaft zusammenwachsen"].

36 Ídem., p. 101. [,,die Angleichung der Kulturen“ „,sondern ihre prinzipielle wechselseitige Übersetzbarkeit"].

37 Íbid.

38 Ídem., pp. 109 s.

39 Ídem., p. 110. 
como Herder proclamaron que en Europa ya no había alemanes, o franceses o ingleses sino solamente europeos, no fue un grito de júbilo sino un lamento. El alemán y el francés se quejaban de la amenazante desdiferenciación de las culturas europeas. Apenas desde hace poco se ha aguzado nuestra conciencia por la imperante necesidad de mantener vivas las diferencias entre las culturas alrededor del mundo y asimismo fomentar el entendimiento pacífico ${ }^{40}$.

No soy de la opinión de que en la actualidad haya que «conservar»o «mantener vivas» las diferencias culturales, ya que las culturas son sistemas en alto grado dinámicos y dables al desarrollo, que no se pueden «conservar» o congelar en cierta condición, ni tampoco se les puede manipular paternalistamente desde algún sitio, ni desde los Estados Unidos ni desde Europa. El desafío al que se enfrenta esta nuestra fase de globalización actual, con sus procesos diferenciadores y desdiferenciadores que corren a la par, con la homogenización cultural y la heterogenización transcultural, consiste en crear las condiciones idóneas para una convivencia a escala mundial, que nos permita convivir en paz y conservando la diferencia cultural. La literatura, en su calidad de estructuración abierta, polilógica y políglota de corte universal, no sólo ofrece un espacio de experimentación sino asimismo un depósito para las formas y normas del conocimiento acerca de la convivencia, que en el futuro deberá ser investigado y analizado con mucha mayor profundidad ${ }^{41}$. ¿No radica aquí una de las tareas, a la vez compleja y prometedora, de la literatura?

Desde esta perspectiva se podría arriesgar una mirada distinta a la pregunta de la traducibilidad de las culturas. En sus célebres composiciones sobre «Die Aufgabe des Übersetzers» [La tarea del traductor], Walter Benjamin coloca la necesidad de la literalidad en la traducción en un contexto que trasciende en mucho el aspecto técnico de cualquier traducción y que implica en última instancia la pregunta por una comunidad, o más todavía, por una comunidad universal:

De acuerdo con esto, la conservación del sentido no requiere forzosamente la traducción literal. El sentido se halla mucho mejor servido por la libertad sin trabas de los malos traductores, incluso con daño para la literatura, y el lenguaje. De manera que esta necesidad, cuya razón es evidente y cuya justificación está muy oculta, debe entenderse forzosamente teniendo en cuenta motivos mejor fundados. Como sucede cuando se pretende volver a juntar los fragmentos de una vasija rota que deben adaptarse en los menores detalles, aunque no sea obligada su exactitud, así también es preferible que la traduc-

40 Íbid.

41 La trilogía Saber sobre/el/vivir, que actualmente ha sido completada, persigue tal finalidad. Aquí mencionaremos los primeros dos tomos: ÜberLebenswissen. Die Aufgabe der Philologie, Berlin, Kulturverlag Kadmos, 2004; ZwischenWeltenSchreiben. Literaturen ohne festen Wohnsitz, Berlin, Kulturverlag Kadmos, 2005. 
ción, en vez de identificarse con el sentido del original, reconstituya hasta en los menores detalles el pensamiento de aquél en su propio idioma, para que ambos, del mismo modo que los trozos de la vasija, puedan reconocerse como fragmentos de un lenguaje superior. Por esta razón, la traducción, en su propósito de comunicar algo, debe prescindir en gran parte del sentido, y el original ya sólo le es indispensable en la medida en que haya liberado al traductor y a su obra del esfuerzo y de la disciplina del comunicante ${ }^{42}$.

Este giro, aparentemente provocador, que habla de prescindir «en gran parte del sentido», adquiere su significado en el momento en que no consideremos como tarea del traductor el hacer desaparecer en lo posible la diferencia (cultural, lingüística, histórica, etc.) entre el «original» y la «traducción», sino que incluyamos esta diferencia en la lengua a la que se traduce, para que de este modo podamos rastrear los contornos y las líneas de los fragmentos y ponerlos de relieve, para que los fragmentos de los respectivos idiomas puedan remitir a la vasija. Si consideramos la silueta y el contorno de esta vasija como aquella unidad y, más aún, comunidad que en un momento dado habría podido existir (en estas reflexiones no tienen mucha importancia los trasfondos filosóficos, religiosos o cabalísticos), entonces podríamos calificar como tarea paradójica del traductor el ir en busca de una comunidad lingüística perdida y asimismo reenfocar y reajustar los fragmentos para poderlos comprender como parte de una historia común.

Esta imagen modelada y fragmentada que presenta Walter Benjamin, así como también la parábola de la caverna de Vargas Llosa y la comunidad que escucha al contador de historias, podrían ser una ficción proyectada hacia la historia remota de la humanidad, pero expresan la doble nostalgia por una tras-lación y una com-posición, por una supervivencia y una convivencia, en la que se genera la comunidad desde la diferencia y fragmentariedad.

Walter Benjamin subraya esto en tanto distingue entre la intención de lo entendido y el modo de entender ${ }^{43}$. Esta diferenciación conforma en cierto sentido un eje que discurre transversalmente a la escición entre significado y significante y toma en consideración, que el objeto al que se remite en las diferentes lenguas puede ser el mismo, pero que las diversas lenguas se diferencian fundamentalmente en el modo de entender, en tanto $-\mathrm{y}$ de esta forma podríamos interpretar las reflexiones de Benjamin- el término alemán «Brot» se ha insertado en un contexto cultural totalmente diferente, en otra historia y en otras semánticas y prácticas que el término francés «pain». A ambos lexemas les corresponde en cierta forma otro «sitio en la vida» e incluso en la convivencia.

42 Benjamin, Walter: «Die Aufgabe des Übersetzers», en (íd.): Gesammelte Schriften, Band IV, 1, editado por Tillmann Rexroth, Frankfurt am Main, Suhrkamp, 1980, p. 18. Traducción al español extraída de Benjamin, Walter: La tarea del traductor, Barcelona, Edhasa, 1971, p. 139.

43 Benjamin, Walter: Die Aufgabe des Übersetzers, op. cit., p. 14. 
Del mismo modo que no debemos tomar al pie de la letra la parábola de la caverna de Vargas Llosa y leerla como una representación acertada de los inicios de la historia de la humanidad ni descalificarla como «tontería ficcional», tampoco deberíamos comprender las reflexiones de Walter Benjamin como un modelo que nos permite considerar una comunidad lingüística como una multiformidad fragmentada y una unidad ensamblable y con ello pensarla desde muchas perspectivas. En ambos modelos se encuentra inherente un boceto de convivencia en el que la lengua y la comunidad, el hablar y el convivir han sido puestos en relación y han sido vinculados a la literatura.

La figura de la comunidad de la lengua se puede pensar aquí también como la configuración de una comunidad mundial. Lo que no necesariamente lleva a tener que aceptar la tesis de la intraducibilidad de las creaciones linguísticas particulares y con ello de los sistemas culturales, por haber llegado a la conclusión de que los términos aparentemente equivalentes de «Brot» y «pain»se encuentren inmersos en otro contexto cultural. Ese prescindir del sentido, del que hace mención Walter Benjamin en el párrafo citado, en última instancia tiene como meta aguzar nuestra conciencia y ajustarla de tal forma, que ya no enfoque el resultado (en cierto sentido literal) de la traducción, sino el proceso de traslación y la traducibilidad entre y bajo las culturas.

Esto nos impide asimismo el acceso directo al objeto de nuestro deseo: ni la lengua del otro ni la cultura del otro nos son simplemente asequibles o quedan a nuestra disposición. La traducción cultural no se limita a expresarse con otras palabras o hablar con las palabras del otro. La traducción más bien expresa con otras palabras las palabras del otro de una manera tal que el o lo otro - aunque sea sólo un futuro lector o un postrer otro- no sea acaparado y engullido (y con ello condenado a desaparecer). Dicho de otra forma: el esbozo de Benjamin hace que pierda validez la asimetría de las relaciones, tal y como la enfrentamos en el privilegio históricamente ajustado del traductor. Porque no sería posible erigir una verdadera comunidad lingüística sobre los cimientos de tales asimetrías, sobre coerciones como las que surgen de parte del español, del portugués y del latín en la primera fase de globalización acelerada, del francés y del inglés, en la segunda y del inglés en la tercera y cuarta fase de globalización acelerada.

Por eso, la verdadera traducción no es lo propio y mucho menos la apropiación del otro, sino más bien algo propio que se presta para el otro o le es afín. En palabras de Benjamin: «Porque en cierto grado todas las grandes escrituras, en más alto grado empero las sagradas, contienen entre líneas una traducción virtual» ${ }^{44}$. Cada lengua, cada cultura es precisamente parte de una comunidad universal, en tanto trae consigo su propia traducción y traducibili-

44 Ídem., p. 21. «Denn in irgendeinem Grade enthalten alle großen Schriften, im höchsten aber die heiligen, zwischen den Zeilen ihre virtuelle Übersetzung»; Benjamin, Walter: La tarea, op. cit., p. 143. 
dad, no importa en qué grado se oriente en una construcción identitaria exclusivista y excluyente.

Por lo tanto, podemos tomar en consideración las reflexiones teóricas sobre la traducción expresadas por Naoki Saki, que proponen una clara diferenciación entre las alocuciones homolingües y heterolingües (homolingual address/heterolingual address) y las distingue de la siguiente manera. Si la primera es «a regime of someone relating herself or himself to others in enunciation whereby the addresser adopts the position representative of a putatively homogeneous language society $\left.{ }^{45}\right\rangle$, la alocución heterolingüe enfoca desde un principio segmentos múltiples y polilingües de escuchas o del público, por lo que en esta comunidad multilingüe, las diversas lenguas se toman en consideración y «traslucen».

Completando y asimismo dándole continuidad a esta tesis, se podría añadir que las lenguas siempre contienen otras lenguas, así como las culturas siempre acarrean consigo otras culturas y con ello logran su propia traducibilidad, o generan las reglas de su propia traducibilidad. La escritora Yoko Tawada, que va y viene entre Alemania y Japón, ha podido liberar de forma muy sutil esta dimensión lingüística en sus textos experimentales ${ }^{46}$.

Es éste el sentido, acuñado por los cauces tan complejos de traducción y traducibilidades (culturales), en el que se debería ver la tarea de la filología, en tanto ya no se concentrase en el encauzamiento nacional-literario de la ficción de una comunidad homolingüe, sino pusiese de relieve la dimensión heterolingüe de la literatura. Porque la presencia de otras lenguas en la propia lengua abre la posibilidad de una relacionalidad múltiple poli-lógica, que caracterizaría y distinguiría - tal y como se podría expresar en términos de la fórmula ya clásica de Benedict Anderson ${ }^{47}$ - las comunidades imaginadas allende lo homolingüe. Sin embargo, una constitución lingüística de tal índole es el requisito fundamental de la convivencia para una comunidad - no solamente en la literatura.

\section{En busca de la fuerza de la futura convivencia}

Sin lugar a dudas, la interrogante de la convivencia en contextos sociales y culturales polilingües se manifiesta de forma especialmente densa en las literaturas sin residencia fija. Desde hace mucho, ya no es un fenómeno de mino-

45 Sakai, Naoki: Translation and Subjectivity. On «Japan» and Cultural Nationalism, Minneapolis-London, University of Minnesota Press, 2009, pp. 3s.

46 Véase para ello los apartados dedicados a Yoko Tawada en el séptimo capítulo de mi volumen ZusammenLebensWissen. List, Last und Lust literarischer Konvivenz im globalen Maßstab.

47 Véase Anderson, Benedict: Imagined Communities. Reflections on the Origin and Spread of Nationalism, London, Verso-New Left Books, 1983. 
rías que puede tratarse al margen de las filologías nacionales, sino que es parte esencial de las literaturas del siglo XXI, tal y como se ha venido perfilando desde hace tiempo ${ }^{48}$ y que, gracias al premio Nobel de Literatura que ganara Herta Müller en 2009 y El Premio del Libro Alemán 2010 otorgado a Melinda Nadj Abonji se ha dado a conocer a un gran público en el espacio de habla alemana.

Sus disposiciones, por su carácter translingüe y transcultural, esto es, que atraviesan diferentes lugares y culturas, hacen presentes o dejan translucir bajo los lugares, otros lugares, bajo las palabras, otras palabras, bajo las culturas, otras culturas, por lo que las literaturas sin residencia fija se caracterizan por los constantes procesos de traducción, que, en el sentido que le diera Roman Jakobson, no se limitan ni a un rewording intralingüe (esto es, una traducción dentro de la misma lengua) ni a un traducir interlingüe (de una lengua a la otra) ${ }^{49}$. Así, las literaturas sin residencia fija siempre mantienen en suspenso las diversas lenguas y culturas y con ello las mantienen en una convivencia (intratextual e intertextual).

Si esta convivencia - tal y como lo ha mostrado la escritora francesa Cécile Wajsbrot 50 - es el requisito fundamental de cualquier escritura creativa en la literatura en general y concretamente, en el nivel intertextual, en las literaturas sin residencia fija pasa a primer plano. Y no sólo lo hace porque en ella (por ejemplo en el nivel biográfico) se tratan preguntas sobre la migración y la convivencia, problemas surgidos a raíz de conflictos solventados abiertamente, o incomprensiones sutiles, desafíos de una simple tolerancia o una absoluta incompatibilidad en el plano del contenido, sino porque en el nivel de la expresión, el material lingüístico generado y utilizado está impregnado y traspasado por interminables procesos translingües de traducción. El trabajo literario ya mencionado de Yoko Tawada, quien escribe tanto en japonés como en alemán ${ }^{51}$ y también las creaciones de otros/as autores/as como Emine Sevgi Özdamar, Terézia Mora, Sherko Fatah, José F. A. Oliver o Ilija Trojanow - quien escribiera un ensayo crítico de gran resonancia sobre la convivencia cultural ${ }^{52}$ - pueden considerarse sintomáticos.

48 Véase para ello Ette, Ottmar: Literatura en movimiento. Espacio y dinámica de la literatura transgresora de fronteras en Europa y América, Madrid, CSIC, 2009, p. 10 y en extenso, ZwischenWeltenSchreiben. Literaturen ohne festen Wohnsitz (2005).

49 Véase Jakobson, Roman: «On linguistic aspects of translation», en (íd.): Selected Writings. II. Word and Language, The Hague-Paris, Mouton, 1971, p. 260.

50 Véase Wajsbrot, Cécile: «Die Bücher kommen aus anderen Büchern zur Welt», en Ette, Ottmar (ed.): Wissensformen und Wissensnormen des Zusammenlebens. Actas del simposio en el Freiburg Institute for Advances Studies, Berlin-New York, Walter de Gruyter, 2011 (en impresión).

51 Véase para ello la reciente publicación de Ivanovic, Christine (ed.): Yoko Tawada. Poetik der Transformation Beiträge zum Gesamtwerk, Mit dem Stück Sancho Pansa von Yoko Tawada, Tübingen, Stauffenburg Verlag, 2010.

52 Trojanow, Ilija y Hoskoté, Ranjit: Kampfabsage. Kulturen bekämpfen sich nicht - sie fließen zusammen, traducción del inglés de heike Schlatterer, München, Karl Blessing Verlag, 2007. 
En cambio, el hecho de tratar todavía y con tanto énfasis este tipo de desarrollos y procesos bajo la rúbrica «Multikulti» - muchas veces en el contexto de debates mal comprendidos sobre multiculturalism llevados a cabo en Estados Unidos- y asimismo, tildarlo de «modelo indefectiblemente malogrado» o «Multikulti ha muerto» sólo se puede ver como un ataque de flojera mental o prueba de pobreza lingüística. Las discusiones que se desatan en Alemania acerca de términos irritadores como «migración» y «Leitkultur» [cultura guía] más allá del debate sostenido por Thilo Sarrazin, en muchos casos carecen de cualquier distancia objetiva y terminológica. Sin embargo, se debería hacer cierto esfuerzo clasificador y distinguir elementalmente (aunque no sin matices) entre una coexistencia multicultural (en la que no hay casi ningún intercambio entre las diversas culturas, sino que preponderantemente viven en espacios separados entre sí), una convivencia intercultural (caracterizada por un intenso diálogo e intercambio, sin que por ello haya transformaciones recíprocas) y una mezcolanza transcultural (que se distingue en gran medida por los procesos de transformación recíproca y el entrecruzamiento de formas y normas de comportamiento cultural). La convivencia en su sentido original no debería de ser un proyecto de asimilimación ni de deculturización, aunque en muchas ocasiones es la política la que exige una convivencia de tal índole. No olvidemos aquí que, bajo el signo de una convivencia en vías de fracasar deberíamos diferenciar al menos entre un conflicto cultural y un choque cultural (y en este último entre destrucción, expulsión y esclavitud) ${ }^{53}$.

Las literaturas universales - y con mayor densidad, las literaturas sin residencia fija - logran desplegar ante nuestros ojos, estética y aiestéticamente, estos cuatro modos de la convivencia, que obviamente no se pueden considerar exentos de conflictos. Y más todavía: gracias a su «saber convivir», conforman el espacio de experimentación para las más diversas formas y normas del saber sobre la convivencia, independientemente de si los escenarios particulares se ubiquan en Alemania, en Suiza, en la Francia contemporánea ${ }^{54} \mathrm{o}$ en el Caribe del siglo XIX ${ }^{55}$. En una compleja interrelación entre lo hallado, lo inventado y lo vivido y también lo vivible se ensayan literariamente, como

53 Véase aquí el estudio clásico de Bitterli, Urs: Die «Wilden» und die «Zivilisierten». Grundzüge einer Geistes- und Kulturgeschichte der europäisch-überseeischen Begegnung, München, Deutscher Taschenbuch Verlag, 1982, pp. 130-160.

54 Véase para ello el libro de Asholt, Wolfgang; Hoock-Demarle, Marie-Claire; Koiran, Linda y Schubert, Katja (eds.): Littérature(s) sans domicile fixe. Literatur(en) ohne festen Wohnsitz, Tübingen, Narr, 2010.

55 Véase para ello la orientación del grupo Emmy-Noether (patrocinado por el DFG) bajo la tutoría de Gesine Müller en materia del Caribe transcolonial y su contribución «Nunca se llega a ser caribeño del todo». Zusammenlebenswissen in transkolonialer Dimension. Oder: karibische Literaturen im 19. Jahrhundert. En Ette, Ottmar (ed.): Wissensformen und Wissensnormen des Zusammenlebens, Actas del simposio en el Freiburg Institute for Advanced Studies, Berlin-New York, Walter de Gruyter, 2011 (en imprenta). 
si fuera un laboratorio de experimentación, los modos de la convivencia en su calidad de modos de la polilógica - como polílogo multilingüe y como entramado poli-lógico de relaciones-. ¿De qué forma se podría definir con más precisión este juego o esta interrelación, que tiene tanta importancia para los diferentes modos y formas de vida de la convivencia?

El término «fuerza» como término elemental de la antropología estética es, tal y como lo ha mostrado Christoph Menke con miras a la historia de la filosofía de habla alemana, de enorme relevancia para las interrogantes que se ocupan de la indeterminación o la arbitrariedad de las experiencias sensitivas. Así, ya en el «Prólogo» a su más reciente estudio sobre la fuerza dice:

Porque a la estética «según Baumgarten» (Herder) en su calidad de teoría de la capacidad sensitiva del sujeto se le opone instantáneamente otra estética: la estética de la fuerza. No comprende lo estético como un reconocimiento y una representación sensitiva (de algo) sino como juego de la expresión -impulsado por una fuerza que no se ejerce como una potencia en prácticas, sino que se autorrealiza: que no reconoce nada, ni representa nada, porque es «oscura», inconsciente; una fuerza, no del sujeto, sino del ser humano en cuanto diferente respecto a sí mismo como sujeto. La estética de la fuerza es una teoría de la naturaleza del ser humano: de su naturaleza estética en cuanto diferente de la cultura de sus prácticas, obtenida por el ejercicio ${ }^{56}$.

Podríamos hacer el intento de elaborar esta «otra estética», esta estética de la fuerza (que puede ser considerada una «realización sin universalidad, más allá de la norma, de la ley y del fin —un juego ${ }^{57}$ ) usando las formas y normas de conocimiento sobre los procesos de la vida, sin emplear el término de experiencia (como «experiencia del juego de la fuerza» ${ }^{58}$ ) y con ello prescindir igualmente del término experiencia estética ${ }^{59}$ (retomado por ejemplo por la estética de la recepción) y lograr una relación entre una estética de la fuerza y la vida desde la perspectiva filológica por medio del término de la $v i$ vencia. Porque en aquella «realización sin universalidad» que seguramente se presenta como un juego serio, pero que por eso no necesariamente tiene que pensarse «más allá de la norma, de la ley y del fin», la literatura, las literaturas, encuentran su espacio lúdico para hacer accesible aquella vivencia de nuevas formas (y normas) del saber de vida en una ejecución experimental del como-si, que de otra manera no se hubieran podido obtener. Gracias a su multiformidad, desenvuelta a lo largo de su historia milenaria en las más di-

56 Menke, Christoph: Kraft. Ein Grundbegriff ästhetischer Anthropologie, Frankfurt am Main, Suhrkamp, 2008, p. 9. Spiel"]

57 Íbid. [,,Vollzug ohne Allgemeinheit, jenseits von Norm, Gesetz und Zweck - ein

58 Ídem., p. 10. [〈Erfahrung des Spiels der Kraft"].

59 Véase para ello Jauß, Hans Robert: Ästhetische Erfahrung und literarische Hermeneutik, Frankfurt am Main, Suhrkamp, 1982. 
versas culturas, la literatura es única y no puede ser sustituida por otras artes o formas de conocimiento, también y precisamente en su calidad de almacén generativo del «saber convivir».

Precisamente en esto no sólo radica la estética de la fuerza, sino más aún, la fuerza de una estética que, en las formas de conocimiento y legados transculturales y translingües de la literatura, se podría denominar su fuerza vital bajo el signo de una vivencia y una revivencia de la misma.

No nos detendremos en los innumerables intentos definitorios del término «vida» que se han venido encadenando históricamente desde la introducción del término «Lebenskraft» [fuerza vital] por el botánico de Mannheim, Friedrich Casimir Medicus ${ }^{60}$ y que se encuentran en íntima relación tanto con la derivación como con la creación terminológica de la «biología» moderna ${ }^{61}$. En el último cuarto del siglo XVIII se discutió con vehemencia en numerosos tratados y escritos polémicos la pregunta por la vida y una o más fuerzas vitales. Así por ejemplo, se puede leer en el Versuch über die Lebenskraft, escrito por J.D. Brandis, quien fuera, según la portada «Herzogl. Braunschweig. Lüneb. Hofrathe, Mitgliede des Ober-Sanitäts-collegiums in Braunschweig, und Brunnenärzte in Driburg» y publicado en 1795 en Hannover:

La muerte suspende, aunque sea aparentemente, todos los efectos recíprocos entre nosotros y el mundo corporal y, poco después, nuestra herramienta divina se convierte en tierra poco animal.

Así tiene que haber, al lado de la composición regular de las partes, una fuerza (o varias fuerzas singulares), que hacen que el cuerpo sea capaz de servirnos como herramienta de comunicación con el mundo corpóreo. La condición, en la que el cuerpo nos puede ofrecer estos servicios se llama vida y las fuerzas que lo posibilitan, fuerzas vitales ${ }^{62}$.

Del hecho de que en las postrimerías del siglo XIX, el término vida - tal y como lo documentan las investigaciones de Michel Foucault - se había convertido en la intersección entre los campos del conocimiento en plena diferenciación de la filosofía y la fisiología, de la ética antropológica y la investigación y la práctica médico-científica, me parece que no han sido considerados lo suficiente las múltiples consecuencias que derivan de él para el término en ciernes de la literatura (o las bellas letras). No es nuestra inten-

60 Véase Kanz, Kai Torsten: «Biologie: die Wissenschaft vom Leben? - Vom Ursprung des Begriffs zum System biologischer Disziplinen (17. bis 20. Jahrhundert)», en Höxtermann, Ekkehard y Hilger, Hartmut H. (eds.): Lebenswissen. Eine Einführung in die Geschichte der Biologie, Rangsdorf, Natur \& Text, 2007, p. 105.

61 En cuanto a la relación con la literatura véase Arz, Maike: Literatur und Lebenskraft. Vitalistische Naturforschung und bürgerliche Literatur um 1800, Stuttgart, M\&P Verlag für Wissenschaft und Forschung, 1996.

${ }^{62}$ Brandis, J. D.: Versuch über die Lebenskraft. J.D. Brandis, Herzogl. Braunschweig. Lüneb. Hofrathe, Mitgliede des Ober-Sanitäts-Collegiums in Braunschweig, und Brunnenärzte in Driburg., Hannover, Im Verlag der Hahn'schen Buchhandlung, 1795, pp. 4 s. 
ción presentar una retrospectiva crítica de la búsqueda de la «verdadera» fuerza vital, que incendió los ánimos de fines del siglo XVIII y que con toda razón fue saldada en las investigaciones biocientíficas algunas décadas después. Más significativo me parece ser el intento de vincular el término de fuerza, en su calidad de término fundamental de la antropología estética, con el de la vida de tal modo que lo estético en su multiformidad trascienda la terminología de la «experiencia» y entre en relación directa con la vida y la vivencia del ser humano (y aquí se logra inferir la alusión a las reflexiones que Mario Vargas Llosa hiciera sobre la relación entre la literatura y la vida).

La literatura dialoga con nosotros - $\mathrm{O}$ se vuelve hacia nosotros y nos encara - en el modo del saber sobre la vivencia. El saber sobre la vivencia y el saber sobre la revivencia en la literatura no es una representación de la realidad, de una realidad literariamente representada, sino la representación de una realidad vivida, que sale a flote y se reconfigura lúdicamente sin cesar en el entreverado del hallar, inventar y vivir entre autores/as, lectores/as, entre texto y contexto, entre las diferentes instancias de la comunicación literaria. La fuerza vital de la literatura se crea por medio de este entreverado, de este tejido vivo que asimismo es el texto y que no se podría concebir sin la dimensión de la vida.

Esto quizás nos lo muestre una de aquellas teorías del texto que son ejemplares en cuanto a las representaciones e interpretaciones pertinentes sobre la aniquilación del sujeto, la muerte del autor, el exorcismo del individuo de cuño occidental del texto (literario). En Le Plaisir du texte, publicado en 1973, Roland Barthes propuso una estética del placer, en la que se definía de la siguiente manera el término texto, indispensable para una teoría del texto:

Texte veut dire Tissur, mais alors que jusqu'ici on a toujours pris ce tissu pour un produit, un voile tout fait, derrière lequel se tient, plus ou moins caché, le sens (la vérité), nous accentuons maintenant, dans le tissu, l'idée générative que le texte se fait, se travaille à travers un entrelacs perpétuel; perdu dans ce tissu — cette texture - le sujet s'y défait, telle une araignée qui se dissoudrait elle-même dans les sécrétions constructives de sa toile, si nous aimions les néologismes, nous pourrions définir la théorie du texte comme une hyphologie (hyphos, c'est le tissu et la toile d'araignée) ${ }^{63}$.

En las interpretaciones que se han realizado hasta la actualidad siempre se ha remitido a la excepcional importancia que tiene una subjetividad en proceso de disolución en este microtexto de la figura «Théorie». Se podría estar de acuerdo con esta representación, porque esta liquidación del sujeto está vinculada a una renuncia a la noción de sujeto y busca, en el sentido que le diera Julia Kristeva, contraponerle a una metafórica que emana del autor, la con-

63 Barthes, Roland: «Le Plaisir du texte», en (íd.): auvres complètes, Tomo II, Paris, Seuil, 1994, p. 1527. 
cepción de una productividad llamada texto ${ }^{64}$. Esta joven, compañera de Roland Barthes en la segunda mitad de los años 60 y primera mitad de los 70 , sustituyó, más allá de todo «significado» emanado del sujeto, el término de intersubjetividad por el término de intertextualidad (que, sin embargo, era equivalente, en el transcurso de las discusiones en los años 70 a las nociones de sujeto y autor). A la vez, una teoría de texto de este cuño le contraponía a las estéticas del autor que se orientaban tradicionalmente en el sujeto y a las filosofías logocéntricas del sujeto (en el sentido de Jacques Derrida ${ }^{65}$ ) una concepción del texto infinitamente abierta, acuñada por différences y différances. Este fragmento, por tanto, ¿no sería más que la formulación especialmente precisa de un teorema postestructuralista, que causó el cambio, quizás decisivo, en el pensamiento de la segunda mitad de los años 60 ?

Este microtexto sobre la teoría elaborado por Barthes encierra mucho más que esto. No debemos pasar por alto, que aquí se traslada una metafórica del texto y de la textura a una metaforología compleja de red que rebasa en mucho la metaforología de la concatenación. La araña en proceso de disolución le confiere a esta red (telaraña) una estructuración organicista y sobre todo una placenteramente viva. La araña le suministra vida al texto. O, dicho de otra manera: hay vida en la red (telaraña). Partiendo de la cadena oracional, tan familiar para los lingüistas, esta imagen nos lleva del tejido, con sus hilos de urdimbre y sus hilos de trama, al teorema y filosofema de una red, en el que ya no hay hilos continuos como en una tela o una alfombra, sino un sinnúmero de interconexiones, que unen todo con todo en una relacionalidad que ya no es rectilínea o dirigida. Lo importante en este reemplazo es, desde el punto de vista elegido, la vivacidad de esta red, que es animada por un ser vivo que suministra, mientras se está desintegrando, su vitalidad y todo su saber de vida a la red. ¿No se podría entonces ver en este microtexto, más allá de un teorema postestructuralista, el desarrollo de una metafórica viva de red, que nos logra trasmitir la imagen de una fuerza vital de la literatura en forma de una relacionalidad viva?

Porque plaisir $d u$ texte —el fractal del título de este volumen se podría traducir asimismo como genitivus obiectivus, genitivus subiectivus, genitivus partitivus o genitivus qualitativus ${ }^{66}$ - se podría considerar, en el contexto de diferentes lógicas (y tradiciones teórico-literarias) como el placer por el texto, el placer del texto mismo, el placer al texto o el placer en el texto y se podría vincular con aquella fuerza estética experimental que apuesta en la multi-

64 Véase para esta metáfora teórico-textual Kristeva, Julia: «La productivité dite texte», en (íd.): Séméiôtikè. Recherches pour une sémanalyse, Paris, Seuil, 1969, pp. 147-184.

65 Véase en relación con el punto de vista barthiano de Derrida, Culler, Jonathan: «At the Boundaries: Barthes and Derrida», en Sussmann, Herbert L. (ed.): At the Boundaries, Boston, Northeastern University Press, 1984, pp. 23-41.

66 Véase para ello mi comentario en Barthes, Roland: Die Lust am Text, op. cit., pp. 163-168. 
plicación lúdica del sentido y de los sentidos. Así se pone en acción un movimiento inconcluso - que Barthes designa, recurriendo a Kristeva, con el término de signifiance - y que también se puede vincular con el giro benjaminiano mencionado con anterioridad («prescindir en gran parte del sentido» ${ }^{67}$ ), porque ambos no quieren ni prescindir, ni negar y mucho menos destruir el sentido - lo que en sí carecería de sentido - sino obtener una multiplicación de sentido y sentidos. Y es precisamente esto lo que caracteriza la verdadera fuerza vital de la literatura.

Una estética del placer concebida como continuación crítica de las reflexiones de Barthes la lograremos solamente proseguir (y asimismo practicar) si logramos considerar las ciencias de la literatura como ciencias de la vida, que asimismo comprenden el saber de vida de la literatura como la verdadera fuerza vital de ella. Para ello podríamos muy bien recurrir a reflexiones y tradiciones como aquellas que exteriorizó Wilhelm Dilthey en Das Erlebnis und die Dichtung:

Satisface al hombre circunscrito por la trayectoria de su vida la nostalgia de vivir las posibilidades de vida que no puede realizar. Le levanta la mirada a un mundo más alto y más fuerte. Y le ocupa todo su ser con la «revivencia» en un curso de procesos psíquicos, desde el goce por el sonido, el ritmo, la plasticidad sensible, hasta la más profunda comprensión del acaecer y de sus relaciones con toda la anchura de su vida. Pues toda auténtica obra poética destaca en el corte de realidad que representa una cualidad de la vida que antes nunca se había visto de este modo. Al mismo tiempo que pone de relieve una conexión causal de procesos o de actos, hace que se revivan los valores que, dentro de la trabazón de la vida, corresponden a un dejar y a las diferentes partes que lo forman. [...] De este modo, la poesía nos abre la compensión de la vida ${ }^{68}$.

Así, podemos aceptar sin cortapisas lo dicho por este precursor y verdadero inventor de las letras, de que en el arte poético y en la literatura todo gira alrededor de la plenitud de la vida. Por su capacidad de poner experimentalmente a disposición del público lector una vivencia, una «revivencia» y un pervivencia, la literatura, en su auto-lógica y su auto-sentido histórica y culturalmente siempre cambiante, se distancia sólo en apariencia de la vida «real» porque, en su calidad de superficie de experimentación propia, puede influir de manera más eficiente, con mayor vigor y persistencia en esta vida. Durante la lectura, la literatura interviene en la vida.

Esto no sólo es válido para la dimensión individual de la comunicación literaria, sino que incluye también la colectiva; dicho de otra manera, la rela-

67 Benjamin, Walter: «Die Aufgabe des Übersetzers», en (íd.): Gesammelte Schriften. Tomo IV, 1, Frankfurt am Main, Suhrkamp, 1980, p. 18.

68 Dilthey, Wilhelm: «Goethe und die dichterische Phantasie», en (id.): Das Erlebnis und die Dichtung. Lessing -Goethe-Novalis-Hölderlin, Göttingen, Vandenhoeck \& Ruprecht, 1985, p. 139. Traducción al español: Dilthey, Wilhelm: Obras IV: Vida y poesía (prólogo y notas de Eugenio Imaz), México, FCE, 1978, p. 140. 
ción entre la literatura y la comunidad. Porque las literaturas universales son el resultado y la vivencia de una actividad tanto transgeneracional como transcultural, que seguramente pertenece, por la variedad de tradiciones desenvueltas a lo largo de los milenios, a una de las actividades más complejas y creativas que han podido concebir los hombres de las más diversas culturas en las latitudes más dispersas. La literatura ya implica, en su enorme acto de traslación que realiza entre las diversas lenguas y diferentes culturas, el esbozo de una comunidad concreta, aunque la vivacidad de la comunicación literaria no se limita a los escritores y el público lector, sino que incluye asimismo en un sentido elemental, la vida del mismo texto. En la poliglosia heterolingüe y translingüe del texto siempre está presente la comunidad, aunque no precisamente como una unidad homogénea.

Las culturas y sociedades desarrollan en cierto momento y dentro de algún contexto un saber con/vivir, que no solamente tiene que enriquecerse continuamente, sino que también se puede perder o ser destruido en mayor o menor medida. Esto puede referirse a cierta sociedad o cierta familia, como en el caso de la Fiesta del Chivo de Mario Vargas Llosa y el ejemplo de la República Dominicana, pero también, tal y como lo muestran las fluctuaciones en el saber convivir entre Francia y Alemania o entre diferentes naciones en los Balcanes, afectar de manera fundamental las relaciones entre diferentes países. La literatura es, en su calidad de acervo altamente dinámico e interactivo y generador de saber de vida aquella formación de conocimiento políglota en la que de forma densa se pueden encontrar gnosemas elementales de un saber vivir, un saber sobre/vivir y un saber con/vivir, que son de crucial importancia para el futuro de nuestro planeta y sus tan diferentes manifestaciones de vida.

Aunque aquí ya no podamos profundizar en algunos gnosemas específicos de un saber sobre/vivir en/de la literatura, hay muchas razones para poder considerar la transformación de la violencia en una fuerza narrativa como el motor esencial de la literatura ${ }^{69}$. Porque la literatura puede contraponerle su capacidad vivificadora al empobrecimiento discursivo radical que podemos descubrir fácilmente en todas las situaciones violentas, a la deliberada reducción a ciertos patrones discursivos prefabricados y antagonismos recíprocamente excluyentes, que en muchas ocasiones han sido enfrentados y radicalizados por las partes interesadas, y encauzar la polisemia y polilógica fundamentada en la misma complejidad de la vida en contra de la propagación de discursos de violencia y violencias discursivas. En sus discursos polilógicos, la literatura es capaz de poner de relieve que las construcciones identitarias apoyadas en mecanismos de exclusión, cuya única meta es la construcción del otro para excluirlo y sustituir esta exclusión por afiliaciones

69 Véase para ello el capítulo ocho en Ette, Ottmar: ZusammenLebensWissen. List, Last und Lust literarischer Konvivenz im globalen Maßstab, op. cit. 
particulares (a una sola concepción religiosa, una sola nación, una etnia o un partido) no son más que eso: construcciones arbitrarias que generan comunidades en el sentido de una comunidad defensiva homolingüe (y latentemente totalitaria).

La literatura pone en movimiento un saber que nos permite contraponerle la fuerza estética de una vida densificada a los reduccionismos totalizantes; en cierto sentido una fuerza vital literaria que de ninguna manera se encuentra escindida de la vida extraliteraria, pero que tampoco es uno con la misma. Una de las tareas prioritarias de la filología debería ser desarrollar esta dimensión prospectiva de la literatura y extenderla a toda la amplitud de la vida.

En su dimensión de continua traslación e integración de otras lenguas y culturas, la literatura nos presenta mecanismos de inclusión que se oponen con eficacia al empobrecimiento discursivo y con ello a la violencia y ensayan las formas de comportamiento alternativo. Si las filologías se comprendieran como ciencias de la vida, entonces podrían ayudarle a las ciencias y a los investigadores de otras formas de conocimiento a una nueva comprensión de la vida y de la convivencia. Pese a los presagios pesimistas, aún no ha terminado el juego de la literatura; ella se encuentra frente a grandes desafíos en esta fase actual de globalización, entre los que cuentan las problemáticas de la convivencia mundial.

La convivencia se podría convertir en uno de los términos clave de la investigación literaria y cultural, si ésta logra encauzar la fuerza vital de la literatura más allá del pasado y de la memoria, hacia el futuro y prepararla para la búsqueda de nuevas formas y normas de la convivencia. Ante esta nueva propuesta metodológica, la filología podría cumplir aquella vieja tarea, en la que Erich Auerbach hiciera tanto hincapié después de la hecatombe de la Segunda Guerra Mundial y lo podría realizar moviéndose por sendas nuevas: «im Universum den Ort des Menschen zu bestimmen [definir el sitio del hombre en el universo]» ${ }^{70}$.

70 Auerbach, Erich: «Philologie der Weltliteratur», en Gesammelte Aufsätze zur romanisches Philologie, München, Francke Verlag, 1967, p. 310. 